\title{
Rhodococcus erythropolis MTHt3 biotransforms ergopeptines to lysergic acid
}

\author{
Michaela Thamhesl', Elisabeth Apfelthaler ${ }^{2}$, Heidi Elisabeth Schwartz-Zimmermann², Elisavet Kunz-Vekiru², \\ Rudolf Krska ${ }^{2}$, Wolfgang Kneifel ${ }^{3}$, Gerd Schatzmayr ${ }^{1}$ and Wulf-Dieter Moll ${ }^{1 *}$
}

\begin{abstract}
Background: Ergopeptines are a predominant class of ergot alkaloids produced by tall fescue grass endophyte Neotyphodium coenophialum or cereal pathogen Claviceps purpurea. The vasoconstrictive activity of ergopeptines makes them toxic for mammals, and they can be a problem in animal husbandry.

Results: We isolated an ergopeptine degrading bacterial strain, MTHt3, and classified it, based on its 16S rDNA sequence, as a strain of Rhodococcus erythropolis (Nocardiaceae, Actinobacteria). For strain isolation, mixed microbial cultures were obtained from artificially ergot alkaloid-enriched soil, and provided with the ergopeptine ergotamine in mineral medium for enrichment. Individual colonies derived from such mixed cultures were screened for ergotamine degradation by high performance liquid chromatography and fluorescence detection. R. erythropolis MTHt3 converted ergotamine to ergine (lysergic acid amide) and further to lysergic acid, which accumulated as an end product. No other tested $R$. erythropolis strain degraded ergotamine. $R$. erythropolis MTHt3 degraded all ergopeptines found in an ergot extract, namely ergotamine, ergovaline, ergocristine, ergocryptine, ergocornine, and ergosine, but the simpler lysergic acid derivatives agroclavine, chanoclavine, and ergometrine were not degraded. Temperature and $\mathrm{pH}$ dependence of ergotamine and ergine bioconversion activity was different for the two reactions.
\end{abstract}

Conclusions: Degradation of ergopeptines to ergine is a previously unknown microbial reaction. The reaction end product, lysergic acid, has no or much lower vasoconstrictive activity than ergopeptines. If the genes encoding enzymes for ergopeptine catabolism can be cloned and expressed in recombinant hosts, application of ergopeptine and ergine degrading enzymes for reduction of toxicity of ergot alkaloid-contaminated animal feed may be feasible.

\section{Background}

Ergot alkaloids occur widely in nature because some ergot alkaloid-producing fungi form intricate associations with plants. Such associations range from mutualistic endosymbiotic life of Neotyphodium or Epichloë species as endophytes in certain grasses [1], and Periglandula species in morning glory [2], to parasitic association of Claviceps species with rye, sorghum and other cereal plants [3]. Ergot alkaloids in plants naturally discourage mammals from feeding, which is one of the proposed advantages for plants to harbour endophytic fungi. The underlying toxicity of ergot alkaloids can be a problem in animal husbandry, and a detoxification technology to increase

\footnotetext{
* Correspondence: dieter.moll@biomin.net

'BIOMIN Research Center, Technopark 1, 3430 Tulln, Austria

Full list of author information is available at the end of the article
}

nutritive value and safety of animal feed would be beneficial.

Ergopeptines typically represent a major proportion of total ergot alkaloids both in sclerotia, which are hard, pigmented mycelium structures formed by Claviceps purpurea as wintering bodies on cereal ears, and in endophyte infected grass. In ergopeptines, cyclic tripeptides are linked to D-lysergic acid by an amide bond (Figure 1). There is tryptophan at position two of the tripeptide in ergotamine (one of the predominant ergopeptines in sclerotia of C. purpurea), whereas there is valine at this position in ergovaline (the predominant ergopeptine in endophyte-infected grass) [4]. Lysergic acid derivatives, including ergopeptines, can undergo epimerisation at the chiral carbon atom C-8. The lefthand rotation isomers $(\mathrm{C}-8(\mathrm{R})$ configuration) are pharmacologically active, and are named with the suffix -ine (e.g., 


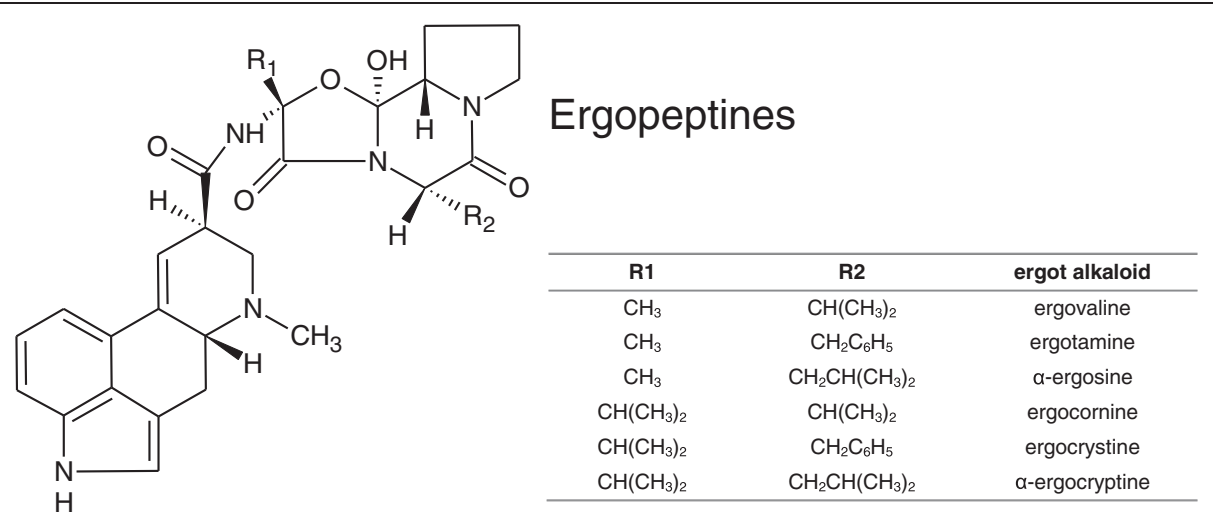<smiles>[R]C(=O)[C@H]1C=C2c3cccc4[nH]cc(c34)C[C@H]2N(C)C1</smiles>

\section{Lysergic acid and ergine}

\begin{tabular}{cc}
\hline $\mathbf{R}$ & ergot alkaloid \\
\hline $\mathrm{NH}_{2}$ & ergine \\
$\mathrm{OH}$ & lysergic acid \\
\hline
\end{tabular}

Figure 1 Structures of ergopeptines, lysergic acid and ergine.

ergotamine) and the right-hand rotation isomers $(\mathrm{C}-8(\mathrm{~S})$ configuration) have lower or no pharmacological activity, and are named with the suffix -inine (e.g., ergotaminine) [5]. Pharmacological activity is based on structural similarity to neurotransmitters serotonin, dopamine, epinephrine or norepinephrine [6], and ergot alkaloids have found a number of medical uses including treatment of migraine [7], Parkinson's disease [8], prolactin-related disorders [9], or in obstetrics $[10,11]$. One important effect of ergot alkaloids in mammals is vasoconstriction: Typical symptoms of ergot alkaloid poisoning of humans in previous centuries included skin discoloration and gangrene of hands or feet, caused by constriction of blood vessels, and called St. Anthony's Fire. Fescue toxicosis, a kind of poisoning that animals may display after consumption of ergot alkaloids by grazing on pastures of tall fescue (Festuca arundinacea) infected with Neotyphodium coenophialum, typically includes symptoms that are related to restricted blood flow in the peripheral vascular system. Such symptoms are changes in body temperature and respiration rate, fat necrosis, dry gangrene or necrosis of tail tips, ear tips or hooves, and may even include loss of hooves [12-14]. Ergopeptines were found to elicit strong vasoconstriction, whereas lysergic acid caused much less or no contractile response [15-19]. An agronomically important symptom of ergot alkaloid poisoning, reduced feed intake and reduced weight gain, has also been related to vasoconstriction $[17,19,20]$.
Ergot alkaloid poisoning of humans is mostly considered a problem of the past, because sclerotia of C. purpurea in rye or other grains can be removed by grain cleaning in mills. In animal nutrition, ergot alkaloid poisoning mostly concerns ruminants grazing on endophyte infected pastures of tall fescue. The economic loss caused by ergot alkaloids in animal husbandry in the United States was estimated in 1993 to be $\$ 600$ million per year [21], and is likely to have increased to over $\$ 1$ billion per year $[13,22]$. It has been attempted to increase the tolerance of animals to ergot alkaloids on tall fescue pastures by providing adsorbents as feed additives [23-26]. As an alternative, biological detoxification through microbial or enzymatic degradation has been investigated for other mycotoxins [27-29]. Ergot alkaloids were also found to be susceptible to microbial degradation, during rumen fermentation [30] or in earthworm intestine [31]. Bioconversion of ergine to lysergic acid by a Rhodococcus equi strain, in the meantime re-classified as $R$. erythropolis [32], has been reported [33], but microbial strains that can transform or metabolise ergopeptines have never been described.

The aim of our work was to explore microbial and enzymatic detoxification of ergot alkaloids with the long term goal of developing a feed additive to ameliorate toxicity of ergot alkaloid-contaminated feed. In our screening for ergot alkaloid-degrading microbial strains, we used ergotamine and ergine as substrates, because 
both substances were commercially available and both substances may be responsible for ergot alkaloid-toxicosis because of their vasoconstrictive activity. We isolated a new bacterial strain, Rhodococcus erythropolis MTHt3, which converted ergopeptines to ergine and further to lysergic acid. Characterisation of the strain's ergopeptine conversion activity suggested that the reactions are likely catalysed by two separate enzymes, which may, if they are identified and produced in recombinant hosts, be suitable for an application to reduce toxicity of ergot alkaloidcontaminated animal feed.

\section{Results}

\section{Isolation and taxonomic assignment of strain MTHt3}

We attempted to isolate ergot alkaloid-degrading microbial strains from samples of soil, rumen fluid, and mites and weevils which infested our stock of sclerotia. Degradation of the ergot alkaloids used as screening substrate, ergotamine and ergine, was repeatedly observed when sample resuspensions in various growth media or buffers were incubated with substrate under aerobic or anaerobic conditions. Biological activity could be distinguished from substrate adsorption by using autoclaved samples as negative controls and by recording time curves. However, none of the strains isolated from such habitats, directly or after enrichment, showed ergotamine degradation activity, and only one of the strains degraded ergine. We also screened 98 bacterial strains and 96 yeast strains from a local, proprietary strain collection for ergotamine or ergine bioconversion activity. Five bacterial and five yeast strains with ergine bioconversion activity, but no strains with ergotamine bioconversion activity, were found. The product of ergine bioconversion was always lysergic acid.

A sample of soil, in which ground sclerotia had been buried three months earlier, was resuspended in M2 buffer, which provides no source of nitrogen, and used for degradation experiments. This soil suspension showed degradation of repeatedly added doses of ergotamine. The first two of four doses of ergotamine, which were added in three days intervals, were only partially degraded. After addition of the third or fourth dose of ergotamine, in parallel samples, ergotamine concentration was reduced to zero within the three days interval. However, cell densities in these mixed culture biotransformation reactions remained low, and no change in optical absorption was observed. The cultures were plated on M2 agar with ergotamine. Colonies and microbial film grown on such plates were washed off and resuspended in M2 buffer with ergotamine, and ergotamine conversion was measured. Reduction of ergotamine concentration in these resuspensions suggested that active strains were able to grow on M2-ergotamine-agar. Two of 158 individually tested colonies showed ergotamine and also ergine degradation. The isolates in the two colonies had identical $16 \mathrm{~S}$ rDNA sequence and were considered sister colonies of the same strain, coded MTHt3. The 16S rDNA sequence was identical with annotated 16S rDNA sequence (1520 bp) in the whole genome sequence of Rhodococcus erythropolis PR4 (GenBank NC_012490), an alkane degrading strain [34], and of $R$. erythropolis CCM 2595 (GenBank NC_022115), a phenol degrading strain [35]. There was a mismatch of one base compared with $16 \mathrm{~S}$ rDNA of $R$. erythropolis type strain DSM $43066^{\mathrm{T}}$ (GenBank X79289): Position 25, according to numbering of PR4 16S rDNA as annotated, is G in DSM $43066^{\mathrm{T}}$, but C in MTHt3, PR4 and CCM 2595. Strain DSM 44595, originally deposited as type strain of Nocardia coeliaca but re-classified as $R$. erythropolis, had its $16 \mathrm{~S}$ rDNA sequenced as part of an effort to make missing sequences of named species available [36], and it is also identical to MTHt3. Compared with the $1520 \mathrm{bp}$ $16 \mathrm{~S}$ rDNA sequence of MTHt3, type strains of other species had, in the available length of their $16 \mathrm{~S}$ sequences, 9 mismatches ( $R$. qingshengii djl-6 ${ }^{\mathrm{T}}$, GenBank DQ090961, and $R$. jialingiae djl-6-2 ${ }^{\mathrm{T}}$, GenBank DQ185597), 12 mismatches ( $R$. baikonurensis GTC 1041 T, GenBank AB071951), 23 mismatches (R. globerulus DSM 4954, GenBank X80619), or more mismatches. None of the other R. erythropolis strains (Table 1) we tested with high biomass concentration and long incubation time converted ergotamine. One strain (DSM 11397) transformed ergine to lysergic acid, but the reaction was slower than with strain MTHt3 (Figure 2).

\section{Characterisation of ergot alkaloid-biodegradation by MTHt3}

To record a time course of ergotamine and ergine bioconversion, $R$. erythropolis MTHt3-biomass was resuspended at lower concentration, $2 \%$ of the maximum $\mathrm{OD}_{600}$ reached in tryptone soya broth (TSB). Ergotamine was degraded quickly, ergine appeared as an intermediate produced by ergotamine degradation, and ergine was converted, more slowly, to lysergic acid (Figure 3). The data shown in Figure 3 are from single biotransformation reactions, but previous biotransformation reactions with different biomass concentrations and sampling times showed similar results. The final lysergic acid concentration was about equimolar to the ergotamine or ergine starting concentration. In order to find out which ergot alkaloids other than the ones used as screening substrates for strain isolation are degraded by R. erythropolis MTHt3, an ergot alkaloid extract from Claviceps purpurea sclerotia was prepared, and MTHt3 was incubated with this extract (Figure 4). Absolute quantification of ergot alkaloid concentrations was difficult because of an apparent increase of concentration over the course of incubation due to buffer evaporation in sample and negative control. Also, concentrations of 
Table 1 List of Rhodococcus strains

\begin{tabular}{lll}
\hline Strain & Properties & Reference \\
\hline R. erythropolis MTHt3 (DSM 25948) & degrades ergot alkaloids & present work \\
R. erythropolis DSM 11397 & nitrile hydratase (NHase) producer & Layh et al. [49] \\
R. erythropolis DSM 20665 & degrades picolilic acid & Koch et al. [77] \\
R. erythropolis DSM 43066 & Goodfellow and Alderson [78] \\
R. erythropolis DSM 43188 & type strain & Metcalfe and Brown [79] \\
R. erythropolis PR4 & fixes nitrogen & Komukai-Nakamura et al. [80] \\
Rhodococcus Sp. DSM 16550 (previously classified as R. erythropolis) & degrades 1-haloalkanes & Kulakova et al. [81] \\
\hline
\end{tabular}

ergot alkaloids and their corresponding C-8 epimeric inine forms [5] had to be summed up as peak areas because the quantities of analytical standards we had available for each substance were not enough for method calibration and accurate quantification. Of the ergot alkaloids that were detectable with a multi-mycotoxin analysis method [37], $R$. erythropolis MTHt3 catalysed bioconversion of all ergopeptines, but not of the lysergic acid derivatives ergometrine (also called ergonovine or ergobasine), agroclavine and chanoclavine. As in the experiment with pure ergotamine (Figure 3), ergopeptine degradation was faster than ergine degradation. No major differences between the transformation rates of the various ergopeptines were apparent. Presumably due to the low concentration of biomass used for reaction with the ergot-extract, ergine concentration increased rather than decreased over the observed incubation period, similar to the concentration of lysergic acid. Correlations of ergotamine and ergine bioconversion activities with $\mathrm{pH}$ and with temperature are shown in Figures 5 and 6. Ergotamine degradation activity was high in the range of $\mathrm{pH} 7.0$ to 10.0 and $25^{\circ} \mathrm{C}$ to $42^{\circ} \mathrm{C}$. Ergine degradation activity was high at $\mathrm{pH} 7.0$, and below $35^{\circ} \mathrm{C}$. Both reactions proceeded only slowly at $\mathrm{pH} 5.0$ or below.

\section{Discussion}

Availability of an ergot alkaloid-degrading bacterial strain might be the starting point for an application in animal nutrition to ameliorate fescue toxicosis of grazing ruminants or ergot alkaloid poisoning of other animals. Fescue toxicosis is a considerable concern in animal husbandry and since several ways of suppressing toxicosis [14], including binding agents for use as feed additives [24], have been investigated, such an application would likely be met with demand from some farmers. Considering a feed additive application for Rhodococcus erythropolis MTHt3, or its enzymes, several questions emerge: Would the
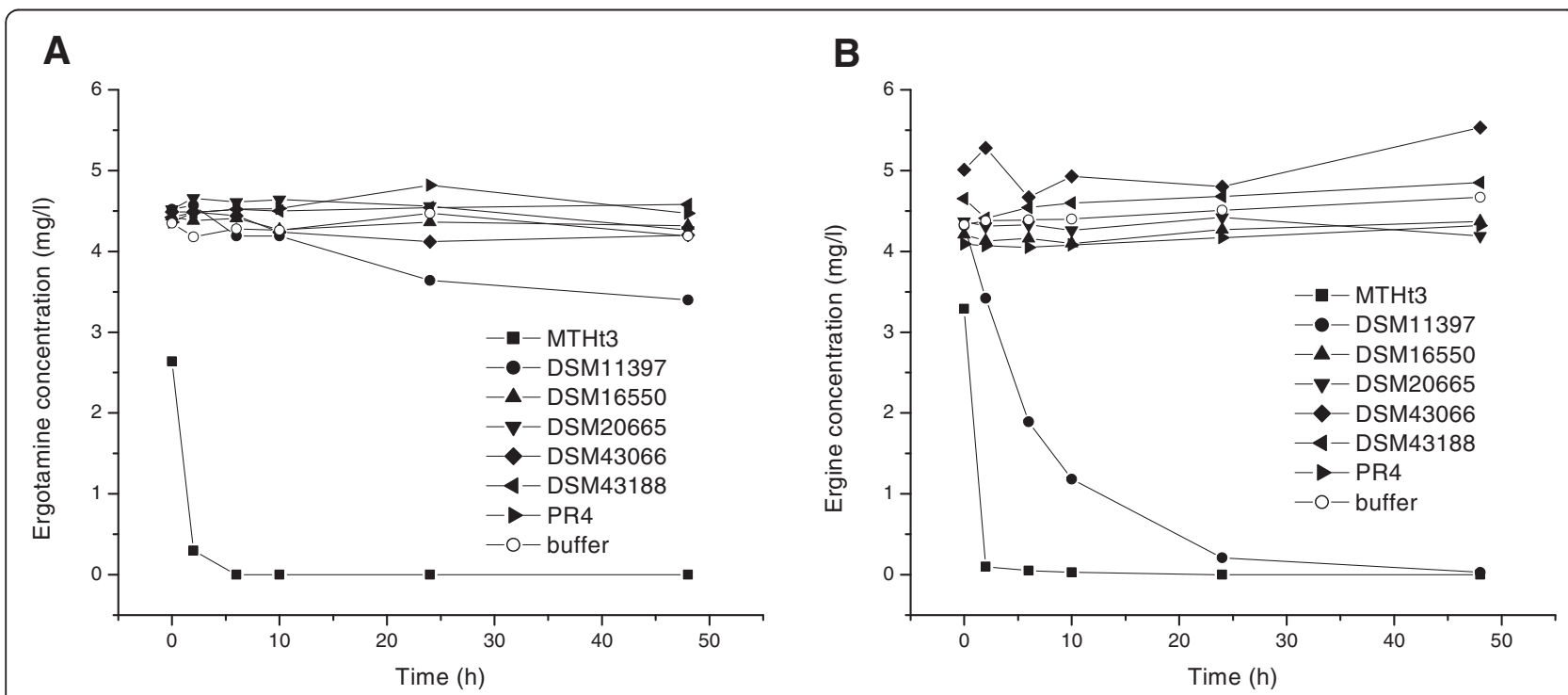

Figure 2 Concentrations of ergotamine (A) and ergine (B) after incubation with Rhodococcus erythropolis strains or buffer. Reactions contained biomass of $R$. erythropolis strains at $\mathrm{OD}_{600 \mathrm{~nm}}=2.0$, which was equivalent to $31 \%$ (MTHt3, DSM 20665, DSM 43188) to 80\% (DSM 11397) of the maximum $\mathrm{OD}_{600 \mathrm{~nm}}$ reached in $\mathrm{TSB}$, in sodium phosphate buffer $\mathrm{pH} 7.0$ with $5 \mathrm{mg} / \mathrm{l}$ ergotamine or ergine, and were incubated at $25^{\circ} \mathrm{C}$ with shaking. Strains are referenced in Table 1. 
R. erythropolis MTHt3

\section{A}

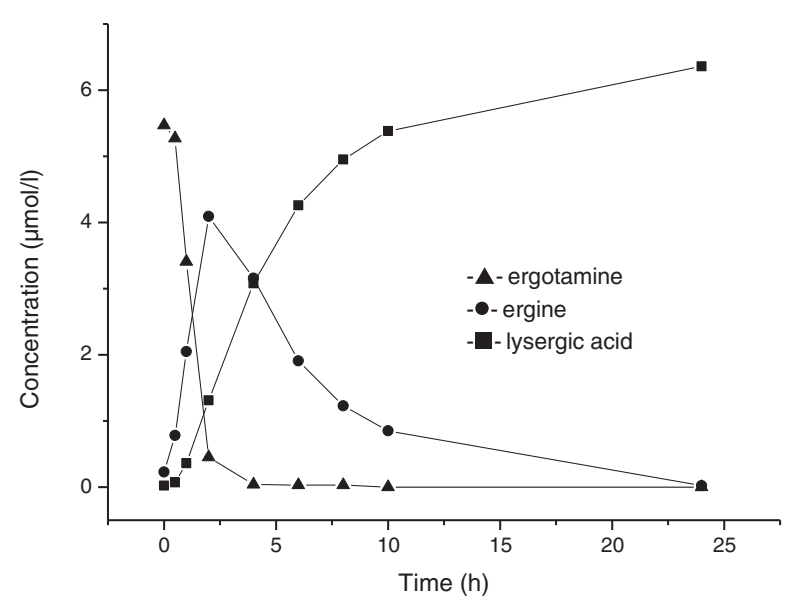

B

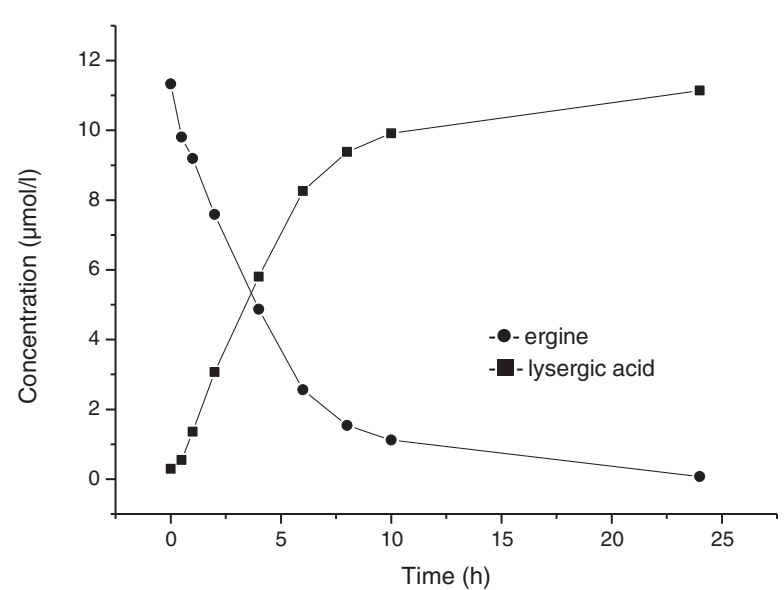

Buffer control
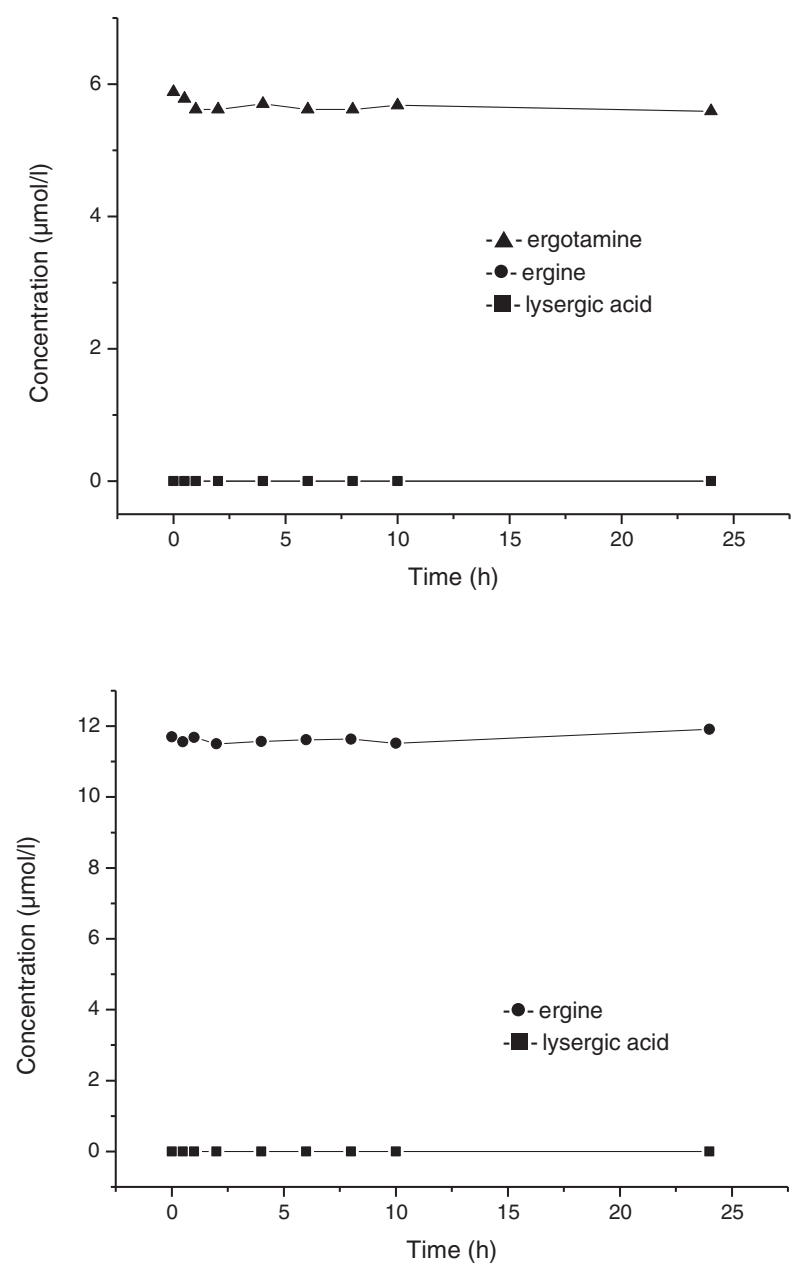

Figure 3 Concentration of ergot alkaloids after incubation of ergotamine (A) or ergine (B) with R. erythropolis MTHt3, or buffer alone. Biomass concentration: $2 \%$ of maximum cell density reached in TSB; buffer: Teorell-Stenhagen buffer pH 7.0; ergot alkaloid starting concentration: $5 \mathrm{mg} / \mathrm{l}(=8.6 \mu \mathrm{M}$ ergotamine or $18.7 \mu \mathrm{M}$ ergine). Plotted data are from single biotransformation reactions.

strain be considered a biological hazard or safe? Is ergot alkaloid-degradation a metabolic activity that is shown by many microbial strains, or is the activity unique for $R$. erythropolis MTHt3? Which of the different ergot alkaloids produced by Claviceps purpurea, Neotyphodium coenophialum, or other fungi, are degraded by the strain and which are persistent? What are the end products of degradation, and will degradation also reduce toxicity? Could an application of the strain as live microbial feed additive be considered, and would activity in animal gastrointestinal tract be high enough to allow degradation of ergot alkaloids before they are absorbed? Would it make sense to attempt cloning of the genes responsible for degradation, and consider production of enzymes for use as feed additive in recombinant hosts?
We repeatedly observed reduction of added ergotamine concentration in some but not all mixed cultures derived from environmental samples. Although we could not isolate more ergopeptine degrading strains from such cultures, microbial ergopeptine degradation activity is likely not unique to $R$. erythropolis MTHt3, but may be more widespread in the environment. $R$. erythropolis MTHt3 or other ergotamine-biotransforming strains may have been able to propagate in our enrichment cultures, because subsequent but not initial doses of ergotamine were consumed in the three day incubation period, but if any growth has occurred it was too low for changes in optical density of the culture to record. Possible effects of acetonitrile, which was used as solvent for ergotamine, were not investigated. A database search with the $16 \mathrm{~S}$ 


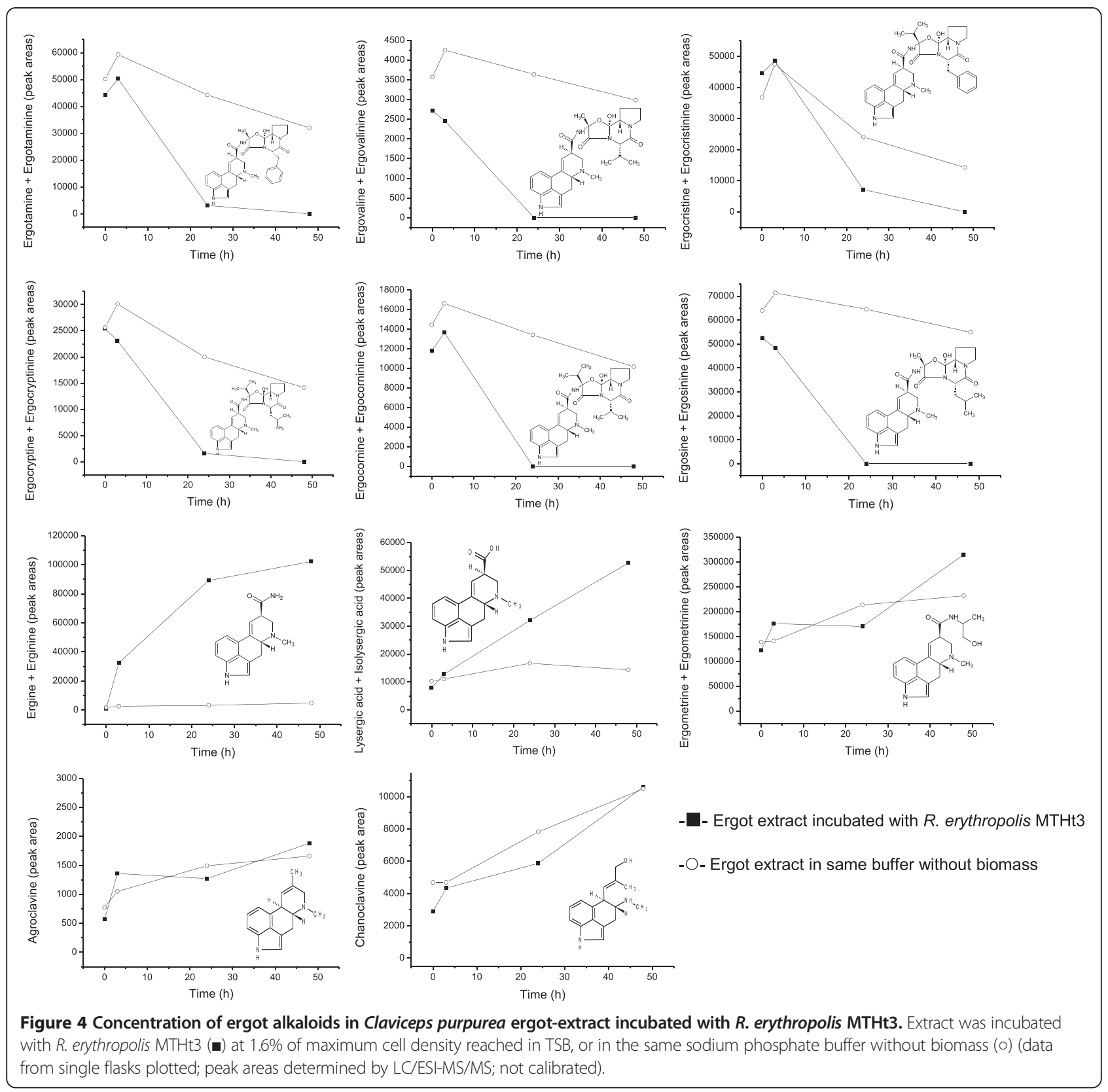

rDNA sequence of strain MTHt3 showed that the strain can be classified with certainty as belonging to the genus Rhodococcus, and probably to the species $R$. erythropolis. Rhodococci are aerobic, gram-positive, non-motile nocardioform actinomycetes [38]. Members of the genus Rhodococcus are widespread in the environment and most common within the microbiota of soil [39]. There are various applications of members of the genus Rhodococcus in industrial and environmental biotechnology, mostly for bioremediation and biodegradation [39-43], but also for bioflocculant and acrylamide production [43]. Some isolates of Rhodococcus species were also described as capable of degrading mycotoxins aflatoxin $\mathrm{B}_{1}[44,45]$, T2 toxin [46] and zearalenone [47,48], and hydrolysis of ergine to lysergic acid has been reported for $R$. equi A4 [33] (re-classified $R$. erythropolis [32]). In the present work, two more Rhodococcus isolates catalysed this ergine to lysergic acid hydrolysis reaction: Our new isolate $R$. erythropolis MTHt3, and one of our reference strains, R. erythropolis DSM 11397, which has been described as nitrile hydratase (NHase) producer [49]. However, degradation or biotransformation of ergopeptines by an isolated microbial strain has, to our knowledge, never been reported before. Our comparison with reference strains showed, that ergopeptine degradation was specific for isolate MTHt3, and not a general physiological activity of $R$. erythropolis. 


\section{Ergotamine}

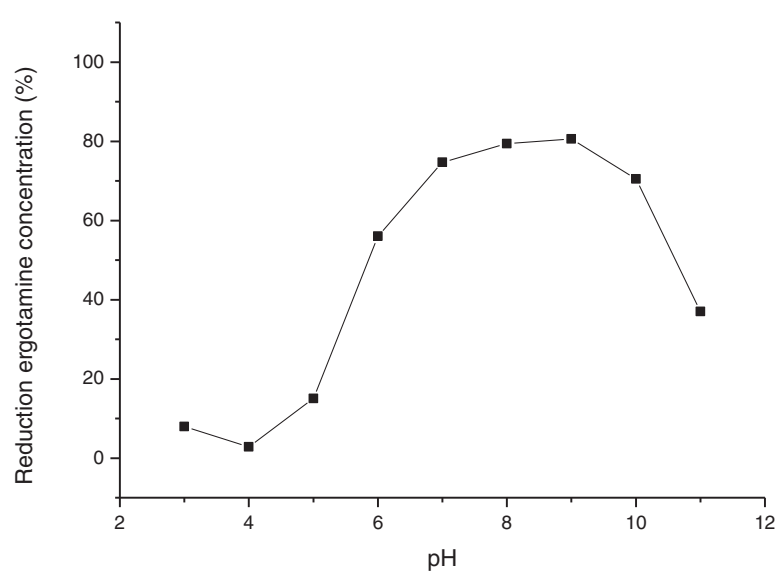

Ergine

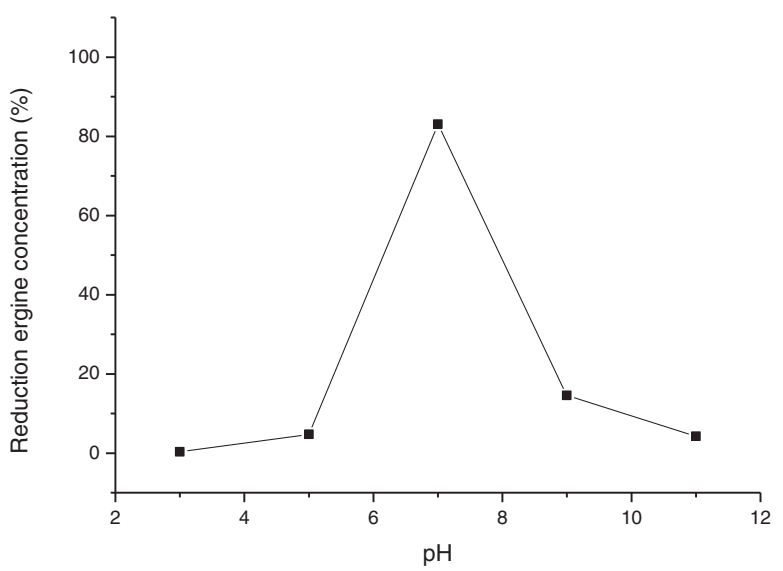

Figure 5 Dependance of ergotamine and ergine biotransformation on $\mathbf{p H}$. R. erythropolis $\mathrm{MTH}+3$ at $2 \%$ of maximum cell density reached in TSB was incubated with $5 \mathrm{mg} / \mathrm{ml}$ ergotamine or ergine in Teorell-Stenhagen buffer at various $\mathrm{pH}$ at $25^{\circ} \mathrm{C}$. Samples from ergotamine biotransformation reactions were taken after $2 \mathrm{~h}$, and samples from ergine biotransformation reactions were taken after $10 \mathrm{~h}$.

$R$. erythropolis is not known to be a pathogen of animals, plants or humans. A full safety evaluation considered $R$. erythropolis strain $\mathrm{C} 2$ safe for use in bioremediation of oil spills [50]. The pathogenic Rhodococcus species, R. equi, a pathogen of horses, and R. fascians, a plant pathogen, are not closely related to MTHt3 and require virulence plasmids for pathogenicity $[51,52]$. R. erythropolis MTHt3 can be considered safe for work in the laboratory and as a possible donor of genes for heterologous expression and recombinant enzyme production, but for use as live microbial feed additive, careful safety evaluation would nevertheless have to be performed.
Biodegradation of ergotamine seemed to be following a well-defined catabolic biotransformation pathway, with ergine as intermediate product and lysergic acid as end product (Figure 3). Incubation of R. erythropolis MTHt3 with an extract of Claviceps purpurea ergots showed that all detectable ergopeptines and ergopeptinines were biotransformed (Figure 4). The data suggest that biotransformation of all ergopeptines follows the same pathway (Figure 7), and a first enzyme in the catabolic pathway may target a molecular moiety that is shared by all ergopeptines. A second enzyme might be an amidase that converts ergine to lysergic acid. Accumulation of

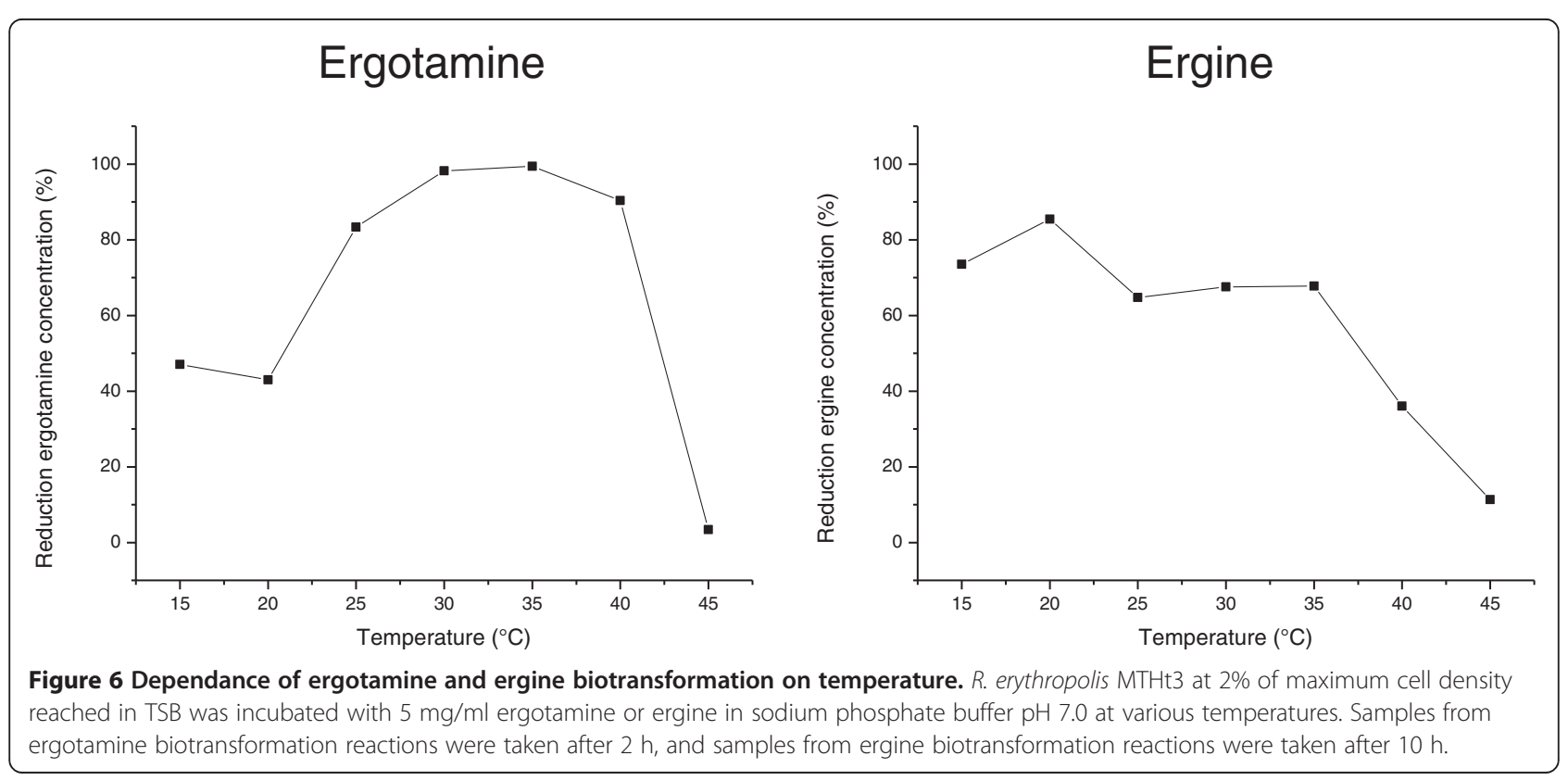




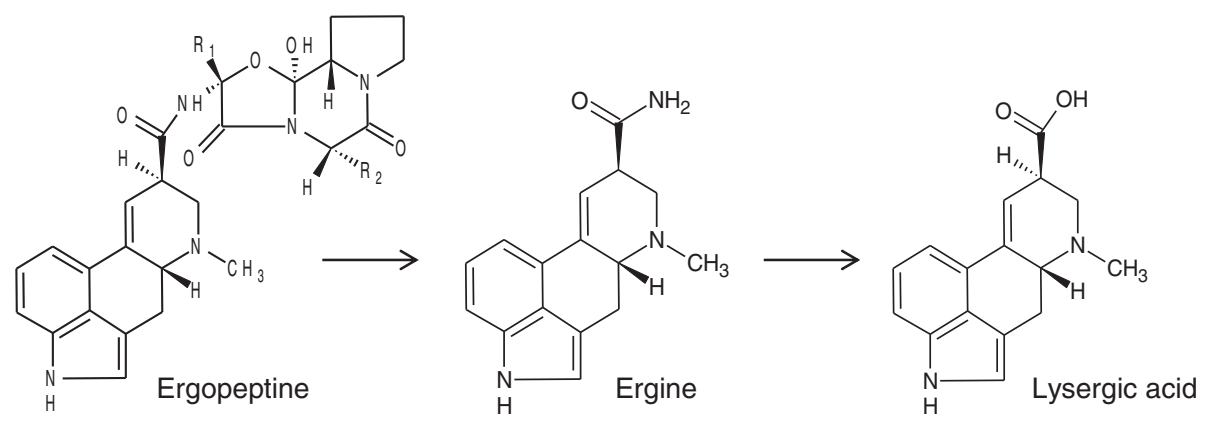

Figure 7 Ergopeptine degradation pathway of $R$. erythropolis MTHt3 $\left(R_{1}\right.$ and $R_{2}$ : see Figure 1$)$.

lysergic acid as end product of ergopeptine catabolism indicates that $R$. erythropolis MTHt3 cannot cleave the ergoline ring system. The benefit of ergopeptine catabolism for $R$. erythropolis MTHt3 may be to utilise fragments of the cyclic tripeptide moiety of ergopeptines, and the amine group of ergine, for cellular metabolism. We have started to work on isolation and identification of reaction products formed from the tripeptide moiety of ergopeptines. For the bacterium, the tripeptide moiety may be an easier target for further catabolism than the ergoline ring. It seems unlikely that after separation from the ergoline ring, fragments of the cyclic tripeptide may still have vasoconstrictive activity since no structural similarity to neurotransmitters is given, but other ergot alkaloid related or unrelated pharmacological activity cannot be ruled out.

Ergopeptines are known as the predominant and most physiologically active ergot alkaloids produced by the grass endophyte $N$. coenophialum or the cereal pathogen C. purpurea [4]. The biodegradation activity of $R$. erythropolis MTHt3 may therefore be able to reduce toxicity of ergot alkaloids in contaminated feed for animals. Our findings that lysergic acid accumulated as an end product of ergopeptine degradation, and that the ergot alkaloids agroclavine, chanoclavine, and ergometrine were not degraded, at least not in the complex mixture we used, pose limitations to possible animal feed detoxification applications of $R$. erythropolis MTHt3. Likely, other ergot alkaloids which are not ergopeptines will also not be degraded, and such alkaloids can also have effects on animals. Agroclavine shows antibiotic activity, interacts weakly with neurotransmitter receptors [53], and has low vasoconstrictive potential [54]. For chanoclavine, in vitro studies suggest a weak affinity for D-2 receptors [55], whereas in vivo chanoclavine has no effect [56]. Ergometrine is one of the main ergot alkaloids produced by C. purpurea [57]. In drunken horse grass (Achnatherum inebrians) infected by the endophytic fungus $N$. gansuense, high levels of ergometrine were also detected [58], but in endophyte-infected tall fescue, only minor concentrations of ergometrine were found
[59]. Ergometrine stimulates uterine contractility and reduces plasma prolactin concentration for a short period after treatment [60,61]. Compared with ergopeptines, ergometrine induces a similar contractile response in a bovine lateral saphenous vein bioassay [62] and a ruminal artery assay [17], but it doesn't have vasoconstrictive effect in a ruminal vein bioassay [17] or cytotoxic effects in cell culture [63].

In tall fescue infected with $N$. coenophialum, ergovaline is known as the predominant ergot alkaloid [64,65], but ergine can occur in similar concentrations [66], and both ergot alkaloids are converted to lysergic acid by $R$. erythropolis MTHt3. Lysergic acid is also a product of ergot alkaloid-metabolism by ruminal microorganisms [67]. Compared to ergopeptines, lysergic acid has lower toxic potential and vascular constriction was only observed with high concentrations of lysergic acid $[15,16]$, or not at all $[17,19]$. In vitro studies indicate that ergovaline, but not lysergic acid, bioaccumulates with repetitive exposure [68], and ergopeptines are persistent in vasoconstriction, whereas lysergic acid and ergoline alkaloids including ergometrine are not [69]. The conclusion of these studies is that conversion of ergopeptines and ergine to lysergic acid should reduce toxicity.

Biodegradation with $R$. erythropolis MTHt3 may cause a transient increase of ergine concentration. Ergine was found to have vasoconstrictive activity similar to ergopeptines in vitro [70], but conversion of ergopeptines to ergine could have in vivo effects that are not obvious to predict. In summary, ergot alkaloid poisoning in animal nutrition is always caused by several alkaloids in a mixture, and composition of this mixture can vary. Biodegradation of ergopeptines with $R$. erythropolis MTHt3, or its enzymes, will likely reduce toxicity, but the degree of toxicity reduction may depend on the original composition of ergot alkaloids in a mixture.

Conversion of ergotamine to lysergic acid was fast with high biomass concentration (Figure 2), but took several hours with lower biomass concentration (Figure 3), and would probably take at least equally long in vivo, for 
instance in bovine rumen. Although release of ergot alkaloids from tall fescue in rumen fluid was reported to proceed slowly over many hours [67], and the $\mathrm{pH}$ (Figure 5) and temperature (Figure 6) conditions that allowed MTHt3 to biotransform ergotamine and ergine covered the range that is considered typical for bovine rumen [71,72], it doesn't seem likely that ergopeptine degradation activity of aerobic bacterium $R$. erythropolis MTHt3 would be sufficient for detoxification in an anaerobic environment such as bovine rumen. However, an animal feed additive application based on recombinant enzymes for ergopeptine and ergine degradation might be feasible. Recombinant enzymes could potentially offer several advantages, including possibilities to use higher activity doses for faster biotransformation, to adapt to reaction conditions by enzyme engineering, to prevent accumulation of an intermediate product by tuning doses of separate enzymes to each other, and to avoid stability and safety issues associated with live strains. We are proceeding with work on identification of ergopeptine degradation genes of $R$. erythropolis MTHt3.

\section{Conclusions}

Our isolation of R. erythropolis MTHt3 and characterisation of its ergot alkaloid-degradation may serve as a new starting point for future development of a technology to reduce toxicity of ergot alkaloid-contaminated animal feed, because degradation of ergopeptines by a microbial isolate has not been reported before. The strain may not be sufficiently active for use as a live microbial feed additive, but its enzymes might be suitable for detoxification, or for production of precursor molecules for pharmaceutical applications. It seems worthwhile to attempt cloning of the genes responsible for ergopeptine and ergine biotransformation.

\section{Methods}

\section{Ergot alkaloids and other chemicals}

Ergotamine D-tartrate was from Sigma-Aldrich (St. Louis, MO, USA). Ergine, erginine, ergotaminine, and lysergic acid were from Alfarma s.r.o. (Cernošice, Czech Republic). Glacial acetic acid (HAc), aqueous ammonia solution, and Methanol (MeOH; LC gradient grade) were from Merck (Darmstadt, Germany). HPLC-grade acetonitrile was from VWR international (West Chester, PA, USA). Ergot alkaloids were dissolved in acetonitrile for use as analytical standards or as stock solutions for degradation experiments, with the exception of ergine which was dissolved in acetonitrile/water $(30 / 70, \mathrm{v} / \mathrm{v})$ for preparation of stock solutions for degradation experiments. Concentrations of stock solutions for degradation experiments were $250 \mathrm{mg} / \mathrm{l}$ for ergotamine and $650 \mathrm{mg} / \mathrm{l}$ for ergine. All other chemicals were from Sigma-Aldrich (St. Louis, MO, USA).

\section{Isolation and cultivation of ergot alkaloid-degrading strain MTHt3}

Sclerotia were obtained from an Austrian mill, where they were collected from naturally contaminated rye by an optical separation system. Sclerotia were ground (Series $\mathrm{II}^{\circ}$ Mill, RomerLabs, Tulln, Austria), and about $200 \mathrm{~g}$ per spot were buried about 8 to $12 \mathrm{~cm}$ deep at three different spots in a field near Königsdorf, Southern Burgenland, Austria, in June. Soil samples from the spots were taken 3 months later, and $2 \mathrm{~g}$ portions of soil were suspended in $18 \mathrm{ml} \mathrm{M} 2$ medium spiked with $5 \mathrm{mg} / \mathrm{l} \mathrm{er-}$ gotamine as a nitrogen source. M2 medium is a modified, nitrogen-free version of Brunner mineral medium (DSMZ medium 457, German Collection of Microorganisms and Cell Cultures; http://www.dsmz.de/microorganisms/medium/pdf/DSMZ_Medium457.pdf) containing $2.44 \mathrm{~g} \mathrm{Na}_{2} \mathrm{HPO}_{4}, 1.52 \mathrm{~g} \mathrm{KH}_{2} \mathrm{PO}_{4}, 0.20 \mathrm{~g} \mathrm{MgSO}_{4} \times 7$ $\mathrm{H}_{2} \mathrm{O}, 0.05 \mathrm{~g} \mathrm{CaCl}_{2} \times 2 \mathrm{H}_{2} \mathrm{O}, 1 \mathrm{~g}$ glucose, and $10.0 \mathrm{ml}$ trace element solution 4 (without EDTA) in $1000 \mathrm{ml}$ distilled water. The soil resuspensions were shaken at $25^{\circ} \mathrm{C}$ and $200 \mathrm{rpm}$ for $14 \mathrm{~d}$, and in $3 \mathrm{~d}$ intervals, samples for high performance liquid chromatography and fluorescence detection (HPLC-FLD) analysis were taken, and fresh ergotamine was added to additional nominal concentration of $5 \mathrm{mg} / \mathrm{l}$. The enrichment cultures were used to make tenfold serial dilutions. Aliquots of dilution stage $10^{\wedge}-2$ to $10^{\wedge}-5$ were spread on plates of M2 (containing $1.5 \%$ agar and $5 \mathrm{mg} / \mathrm{l}$ ergotamine) and incubated at $25^{\circ} \mathrm{C}$ until colonies appeared. Individual colonies were streaked on fresh M2-ergotamine-plates to obtain pure cultures. Single colonies from these plates were inoculated into $5 \mathrm{ml} \mathrm{M} 2$ medium with $5 \mathrm{mg} / \mathrm{l}$ ergotamine or ergine. These cultures were incubated at $25^{\circ} \mathrm{C}$ and $200 \mathrm{rpm}$ in the dark for $7 \mathrm{~d}$, and concentrations of ergotamine and ergine were determined by HPLC-FLD. Ergotamine degrading isolate MTHt3 was subsequently cultivated in TSB (Oxoid Limited, Hampshire, UK) at $25^{\circ} \mathrm{C}$ and $200 \mathrm{rpm}$, and cryo-conserved in this medium with $10 \%$ glycerol at $-80^{\circ} \mathrm{C}$. Strain MTHt3 was deposited at DSMZ with the assigned number DSM 25948.

\section{Strain identification}

Taxonomic assignment of strain MTHt3 was initially made by PCR amplification of $16 \mathrm{~S}$ rDNA using universal primers 27F (5' - AGA GTT TGA TCM TGG CTC AG -3') and 1492R (5' - TAC GGY TAC CTT GTT ACG ACT T -3') [73], and sequencing. For PCR amplification, MTHt3 was grown overnight in TSB as described, and $1 \mu \mathrm{l}$ culture was added directly to PCR reaction buffer $\left(10 \mu \mathrm{l} 5 \mathrm{x}\right.$ Phusion $^{\text {Tw }}$ HF buffer, $200 \mu \mathrm{M}$ of each dNTP, $0.5 \mu \mathrm{M}$ of each primer and $1 \mathrm{U}$ of Phusion $^{\mathrm{mm}}$ high-fidelity DNA polymerase (Finnzymes Oy, Vantaa, Finland); final volume: $50 \mu \mathrm{l}$ ). PCR was performed in a thermocycler (Mastercycler gradient, Eppendorf, Hamburg, Germany) according to 
the following program: 1 cycle of $10 \mathrm{~min}$ at $98^{\circ} \mathrm{C} ; 35 \mathrm{cy}$ cles of $10 \mathrm{~s}$ at $98^{\circ} \mathrm{C}, 20 \mathrm{~s}$ at $53.7^{\circ} \mathrm{C}, 45 \mathrm{~s}$ at $72^{\circ} \mathrm{C}$; and a final extension step at $72^{\circ} \mathrm{C}$ for $10 \mathrm{~min}$. PCR product was purified by QIAquick PCR purification kit (Qiagen) according to the manufacturer's instructions. Sanger sequencing (primers $27 \mathrm{~F}$ and $1492 \mathrm{R}$ ) was performed by VBC-BIOTECH Service GmbH (Vienna, Austria). More recently, the whole genome of Rhodococcus erythropolis MTHt3 was sequenced to support ergopeptine biotransformation gene identification and cloning. Genomic DNA of strain MTHt3 was prepared from the biomass pellet of an overnight culture $\left(100 \mathrm{ml} \mathrm{TSB}, 25^{\circ} \mathrm{C}\right.$, $200 \mathrm{rpm}$ ) by using Qiagen Genomic-tip 500/G kit (Hilden, Germany). Cell lysis was enhanced by addition of mutanolysin $(200 \mathrm{U} / \mathrm{ml})$ and by prolonging incubation to $4 \mathrm{~h}$ at $37^{\circ} \mathrm{C}$. Whole-genome sequencing was performed by LGC Genomics GmbH (Berlin, Germany) using Roche 454 technology. The previously obtained $16 \mathrm{~S}$ rDNA sequence was confirmed and extended to $1520 \mathrm{bp}$, matching the annotation of R. erythropolis PR4 (GenBank NC_012490) and R. erythropolis CCM 2595 (GenBank NC_022115) whole genome sequences. Taxonomic assignment was made by submitting $16 \mathrm{~S} \mathrm{rDNA}$ sequence to the ribosomal database project (https:// rdp.cme.msu.edu/index.jsp [74]) for alignment with fulllength $16 \mathrm{~S}$ sequences of type strains, to EzTaxon (http:// www.ezbiocloud.net/eztaxon [75]), and to BLAST (http:// blast.ncbi.nlm.nih.gov/Blast.cgi).

\section{Biodegradation of ergotamine and ergine with other Rhodococcus erythropolis strains}

Bacterial strains (Table 1), presently classified or at the time of use classified as $R$. erythropolis, were obtained from DSMZ (http://www.dsmz.de/). Strains were grown overnight in TSB $\left(25^{\circ} \mathrm{C}, 200 \mathrm{rpm}\right)$, biomass was collected by centrifugation $\left(2655 \times \mathrm{g}, 20^{\circ} \mathrm{C}, 5 \mathrm{~min}\right)$ and resuspended in the same volume of $50 \mathrm{mM}$ sodium phosphate buffer $\mathrm{pH}$ 7.0. These resuspensions and the same buffer were mixed to make $10 \mathrm{ml}$ aliquots with optical density $\left(\mathrm{OD}_{600 \mathrm{~nm}}\right) 2.0$, and spiked with $5 \mathrm{mg} / \mathrm{l}$ ergotamine or ergine. Controls were the same spiked buffer without inoculation, and incubated under the same conditions $\left(25^{\circ} \mathrm{C}, 200 \mathrm{rpm}\right)$. Samples were taken periodically, processed as described below, and stored at $-20^{\circ} \mathrm{C}$ until analysis by HPLC-FLD.

\section{Incubation of $R$. erythropolis MTHt3 with ergot extract}

A suspension of MTHt3 was made by inoculating the strain in TSB and cultivating for $20 \mathrm{~h}$, collecting biomass from $5 \mathrm{ml}$ culture by centrifugation $(2655 \times \mathrm{g} ; 10 \mathrm{~min})$, and resuspending it in $5 \mathrm{ml} 50 \mathrm{mM}$ sodium phosphate buffer pH 7.0. Ergot extract was prepared by shaking $20 \mathrm{~g}$ ergot meal, obtained as described above, with $80 \mathrm{ml}$ acetonitrile/water $(1 / 1, \mathrm{v} / \mathrm{v})$ for $2 \mathrm{~h}$ at room temperature.
This crude extract was filtered ("White Ribbon Filter", Grade 589/2: 4-12 $\mu$ m; Whatman plc, Kent, UK), concentrated almost to dryness by rotary evaporation (Heidolph VV2011, Schwabach, Germany) and lyophilised (Christ, Osterode am Harz, Germany). Lyophilisate was dissolved (125 $\mathrm{mg}$ in $4 \mathrm{ml}$ acetonitrile/water $(1: 1, \mathrm{v} / \mathrm{v}))$ and filter-sterilised (Filtropur S, $0.2 \mu \mathrm{m}$, Sarstedt, Nümbrecht, Germany). One $\mathrm{ml}$ of this ergot extract was added to $0.08 \mathrm{ml} \mathrm{MTHt} 3$ suspension and $3.92 \mathrm{ml}$ $50 \mathrm{mM}$ sodium phosphate buffer $\mathrm{pH} 7.0$, and the spiked suspension was incubated at $25^{\circ} \mathrm{C}$ and $200 \mathrm{rpm}$. Samples were taken and analysed by liquid chromatography/electrospray ionisation tandem mass spectrometry (LC/ESI-MS/MS) as previously described [37]. Negative control samples were taken from parallel incubation of the same, sterile ergot extract in the same buffer volume without MTHt3.

\section{Time course of ergotamine and ergine bioconversion}

Strain MTHt3 was grown for $17 \mathrm{~h}$ in TSB at $25^{\circ} \mathrm{C}$ and $200 \mathrm{rpm}$. Biomass was harvested by centrifugation $\left(2655 \times \mathrm{g}, 20^{\circ} \mathrm{C}, 5 \mathrm{~min}\right)$ and resuspended in the same volume Teorell-Stenhagen universal buffer $\mathrm{pH} 7.0$ (citrate, phosphate and borate; [76]). The MTHt3 suspension was diluted $1 / 50$ with Teorell-Stenhagen universal buffer $\mathrm{pH} 7.0$, spiked with $5 \mathrm{mg} / \mathrm{l}$ ergotamine or ergine, and incubated at $25^{\circ} \mathrm{C}$ and $200 \mathrm{rpm}$. Samples were taken periodically, processed, and analysed by HPLC-FLD as described below.

\section{$\mathrm{pH}$ and temperature dependence of ergotamine and ergine bioconversion}

An overnight culture of MTHt3 was prepared as described above. Biomass was harvested by centrifugation $\left(2655 \times \mathrm{g}, 20^{\circ} \mathrm{C}, 5 \mathrm{~min}\right.$ ) and resuspended in the same volume Teorell-Stenhagen universal buffer $\mathrm{pH} 7.0$ for the $\mathrm{pH}$ dependence experiment, or in $50 \mathrm{mM}$ sodium phosphate buffer $\mathrm{pH}$ 7.0, for the temperature dependence experiment. Teorell-Stenhagen universal buffer prepared at $\mathrm{pH}$ values from 3.0 to 11.0 was spiked with ergotamine or ergine (final concentration: $5 \mathrm{mg} / \mathrm{l}$ ), inoculated with $1 / 50$ volume MTHt3 suspension, and incubated at $25^{\circ} \mathrm{C}$ without shaking. At the end of the incubation period, $\mathrm{pH}$ was measured and verified. Reference reactions were identical but without biomass. Shaking was omitted because previous results showed that shaking had no effect on ergot alkaloid-biotransformation by MTHt3, but affected buffer $\mathrm{pH}$, presumably due to higher carbon dioxide exposure. For determination of correlation of activity with temperature, $50 \mathrm{mM}$ sodium phosphate buffer, $\mathrm{pH} 7.0$, spiked with $5 \mathrm{mg} / \mathrm{l}$ ergotamine or ergine, was set to temperatures from $15^{\circ} \mathrm{C}$ to $45^{\circ} \mathrm{C}$ by incubation in water baths, inoculated with $1 / 50$ volume MTHt3 suspension, and further incubated without 
shaking. Negative controls, identical but without biomass, were incubated at the same temperatures. Samples from the $\mathrm{pH}$ and temperature experiments were taken at several time points and processed for HPLC-FLD analysis as described below. Time points $2 \mathrm{~h}$ for ergotamine biotransformation and $10 \mathrm{~h}$ for ergine biotransformation were chosen for the graphs in Figures 5 and 6, because biotransformations were just complete or nearly complete under the reaction conditions giving the highest activities.

\section{Sample analysis by high performance liquid chromatography and fluorescence detection (HPLC-FLD)} Concentrations of ergotamine and ergine, their epimericinine forms and lysergic acid were determined by HPLCFLD on an HP 1100 system (Agilent, Waldbronn, Germany) equipped with a G1321A fluorescence detector. Samples from degradation experiments were centrifuged $\left(10621 \times \mathrm{g}, 20^{\circ} \mathrm{C}, 10 \mathrm{~min}\right)$, and $320 \mu \mathrm{l}$ aliquots of supernatant were transferred to amber glass vials. Eighty $\mu \mathrm{l}$ acetonitrile was added, and the mixtures were vortexed and stored at $-20^{\circ} \mathrm{C}$ until analysis. Mobile phases A (methanol:water 10/90, v/v) and B (methanol:water 80/20, v/v) contained $25 \mathrm{mM}$ glacial acetic acid and were set to $\mathrm{pH} 8.0$ with ammonia solution. The column thermostat of the HPLC system was kept at $20^{\circ} \mathrm{C}$, the flow rate was set to $0.5 \mathrm{ml} / \mathrm{min}$, and the injection volume to $10 \mu \mathrm{l}$. Elution was performed in gradient elution mode (0 min: 30\% B, 2 min: 100\% B, 4 min: $100 \%$ B, 4.2 min: $30 \%$ B, 7 min: $30 \%$ B for lysergic acid, ergine, and erginine; or 0 min: $30 \% \mathrm{~B}, 2$ min: $100 \%$ B, 5.5 min: $100 \%$ B, 5.6 min: 30\% B, 8.5 min: 30\% B for lysergic acid, ergine, ergotamine and their epimers) on a Gemini C18 column $(50 \times 2 \mathrm{~mm}, 5 \mu \mathrm{m}$ particle size; Phenomenex, Aschaffenburg, Germany). The fluorescence detector was set to excitation at $310 \mathrm{~nm}$ and emission at $415 \mathrm{~nm}$. Concentrations of ergot alkaloids and their respective epimers were added up.

Nucleotide sequence accession number The $16 \mathrm{~S}$ rDNA gene sequence of $R$. erythropolis MTHt3 was deposited at NCBI GenBank under accession number KM047507.

The study was approved by the BIOMIN R\&D board.

\section{Competing interests}

MT, GS and W-DM are employees of BIOMIN Holding GmbH, a company active in the business field of animal feed additives. EA, HES-Z, EK-V and RK are affiliated with a Christian Doppler Laboratory, which is co-sponsored by BIOMIN.

\section{Authors' contributions}

MT and W-DM designed the experiments and wrote the manuscript. MT carried out the microbiological experiments and data analysis. EA and HES-Z performed the analytical measurements and were consulted by EK-V and RK. WK and GS advised on study design and direction. All authors read and approved the final manuscript.

\section{Acknowledgements}

We would like to thank Sabine Baumgartner for helping us with the lyophilisation of the ergot alkaloid extract, and Michael Sulyok and Martin Hafner for LC-MS/MS analysis of samples by the multi-mycotoxin method. Catherine Anne Moll corrected the English grammar. This work was supported in part by the Austrian Research Promotion Agency FFG and the Christian Doppler Society.

\section{Author details}

${ }^{1}$ BIOMIN Research Center, Technopark 1, 3430 Tulln, Austria. ${ }^{2}$ Department for Agrobiotechnology (IFA-Tulln), Christian Doppler Laboratory for Mycotoxin Research, Center for Analytical Chemistry, University of Natural Resources and Life Sciences (BOKU) Vienna, Konrad Lorenz Straße 20, 3430 Tulln, Austria. ${ }^{3}$ Christian Doppler Laboratory for Innovative Bran Biorefinery, University of Natural Resources and Life Sciences, Muthgasse 18, 1190 Vienna, Austria.

Received: 14 August 2014 Accepted: 11 March 2015 Published online: 28 March 2015

\section{References}

1. Schardl CL, Florea S, Pan J, Nagabhyru P, Bec S, Calie PJ. The epichloae: alkaloid diversity and roles in symbiosis with grasses. Curr Opin Plant Biol. 2013;16(4):480-8

2. Steiner U, Leibner S, Schardl CL, Leuchtmann A, Leistner E. Periglandula, a new fungal genus within the Clavicipitaceae and its association with Convolvulaceae. Mycologia. 2011;103(5):1133-45.

3. Tudzynski P, Scheffer J. Claviceps purpurea: molecular aspects of a unique pathogenic lifestyle. Mol Plant Pathol. 2004;5(5):377-88.

4. Schardl CL, Panaccione DG, Tudzynski P. Ergot alkaloids-biology and molecular biology. Alkaloids Chem Biol. 2006;63:45-86.

5. Krska R, Crews $C$. Significance, chemistry and determination of ergot alkaloids: A review. Food Addit Contam. 2008;25(6):722-31.

6. Tudzynski P, Correia T, Keller U. Biotechnology and genetics of ergot alkaloids. Appl Microbiol Biotechnol. 2001;57(5-6):593-605.

7. Tfelt-Hansen P, Saxena PR, Dahlof C, Pascual J, Lainez M, Henry P, et al. Ergotamine in the acute treatment of migraine: a review and European consensus. Brain. 2000;123(Pt 1):9-18.

8. Brooks DJ. Dopamine agonists: their role in the treatment of Parkinson's disease. J Neurol Neurosurg Psychiatry. 2000;68(6):685-9.

9. Crosignani PG. Current treatment issues in female hyperprolactinaemia. Eur J Obstet Gynecol Reprod Biol. 2006;125(2):152-64.

10. Dudley HW, Moir C. The substance responsible for the traditional clinical effect of ergot. Br Med J. 1935;1(3871):520-3.

11. de Groot AN, van Dongen PW, Vree TB, Hekster YA, van Roosmalen J. Ergot alkaloids. Current status and review of clinical pharmacology and therapeutic use compared with other oxytocics in obstetrics and gynaecology. Drugs. 1998;56(4):523-35.

12. Hemken RW, Boling JA, Bull LS, Hatton RH, Buckner RC, Bush LP. Interaction of environmental temperature and anti-quality factors on the severity of summer fescue toxicosis. J Anim Sci. 1981;52(4):710-4.

13. Strickland JR, Looper ML, Matthews JC, Rosenkrans JI CF, Flythe MD, Brown KR, et al. St. Anthony's Fire in livestock: Causes, mechanisms, and potential solutions. J Anim Sci. 2011;89(5):1603-26.

14. Aiken GE, Strickland JR. Forages and pastures symposium: managing the tall fescue-fungal endophyte symbiosis for optimum forage-animal production. J Anim Sci. 2013;91(5):2369-78.

15. Klotz JL, Bush LP, Smith DL, Shafer WD, Smith LL, Vevoda AC, et al. Assessment of vasoconstrictive potential of D-lysergic acid using an isolated bovine lateral saphenous vein bioassay. J Anim Sci. 2006;84(11):3167-75.

16. Klotz JL, Kirch BH, Aiken GE, Bush LP, Strickland JR. Effects of selected combinations of tall fescue alkaloids on the vasoconstrictive capacity of fescue-naive bovine lateral saphenous veins. J Anim Sci. 2008;86(4):1021-8.

17. Foote AP, Harmon DL, Strickland JR, Bush LP, Klotz JL. Effect of ergot alkaloids on contractility of bovine right ruminal artery and vein. J Anim Sci. 2011;89(9):2944-9.

18. Klotz JL, Brown KR, Xue Y, Matthews JC, Boling JA, Burris WR, et al. Alterations in serotonin receptor-induced contractility of bovine lateral saphenous vein in cattle grazing endophyte-infected tall fescue. J Anim Sci. 2012;90(2):682-93. 
19. Egert AM, Kim DH, Schrick FN, Harmon DL. Dietary exposure to ergot alkaloids decreases contractility of bovine mesenteric vasculature. J Anim Sci: Klotz JL; 2014

20. Foote AP, Kristensen NB, Klotz JL, Kim DH, Koontz AF, McLeod KR, et al Ergot alkaloids from endophyte-infected tall fescue decrease reticuloruminal epithelial blood flow and volatile fatty acid absorption from the washed reticulorumen. J Anim Sci. 2013;91(11):5366-78

21. Hoveland CS. Importance and economic significance of the Acremonium endophytes to performance of animal and grass plant. Agric Ecosyst Environ. 1993:44:3-12.

22. Panaccione DG, Johnson RD, Wang J, Young CA, Damrongkool P, Scott B, et al. Elimination of ergovaline from a grass-Neotyphodium endophyte symbiosis by genetic modification of the endophyte. Proc Natl Acad Sci U S A. 2001;98(22):12820-5.

23. Chestnut AB, Anderson PD, Cochran MA, Fribourg HA, Gwinn KD. Effects of hydrated sodium calcium aluminosilicate on fescue toxicosis and mineral absorption. J Anim Sci. 1992;70(9):2838-46.

24. Huebner HJ, Lemke SL, Ottinger SE, Mayura K, Phillips TD. Molecular characterization of high affinity, high capacity clays for the equilibrium sorption of ergotamine. Food Addit Contam. 1999;16(4):159-71.

25. Reed KFM, Vaughan $J$, Cummins $L$, Moore DD. Impact of mycotoxins and of a mycotoxin deactivator on alpacas grazing perennial ryegrass infected with wild endophyte (Neotyphodium spp.). Anim Prod Sci. 2010;50:902-8.

26. Reed KFM, Cummins LJ, Moore DD, Clark AJ. Performance of Coopworth ewe lambs exposed to low levels of ryegrass endophyte (Neotyphodium lolii) alkaloids and allowed access to a mycotoxin deactivator. Anim Prod Sci. 2011;51:225-32.

27. Karlovsky P. Biological detoxification of fungal toxins and its use in plant breeding, feed and food production. Nat Toxins. 1999;7(1):1-23.

28. Karlovsky P. Biological detoxification of the mycotoxin deoxynivalenol and its use in genetically engineered crops and feed additives. Appl Microbiol Biotechnol. 2011;91(3):491-504.

29. Hartinger D, Moll WD. Fumonisin elimination and prospects for detoxification by enzymatic transformation. World Mycotoxin J. 2011;4(3):271-83.

30. Moyer JL, Hill NS, Martin SA, Agee CS. Degradation of ergoline alkaloids during in vitro ruminal digestion of tall fescue forage. Crop Sci. 1993:33:264-6.

31. Rattray RM, Perumbakkam S, Smith F, Craig AM. Microbiomic comparison of the intestine of the earthworm Eisenia fetida fed ergovaline. Curr Microbiol. 2010;60(3):229-35

32. Vejvoda V, Sveda O, Kaplan O, Prikrylova V, Elisakova V, Himl M, et al. Biotransformation of heterocyclic dinitriles by Rhodococcus erythropolis and fungal nitrilases. Biotechnol Lett. 2007;29(7):1119-24.

33. Martinkova L, Kren V, Cvak L, Ovesna M, Prepechalova I. Hydrolysis of lysergamide to lysergic acid by Rhodococcus equi A4. J Biotechnol. 2000;84(1):63-6.

34. Sekine M, Tanikawa S, Omata S, Saito M, Fujisawa T, Tsukatani N, et al. Sequence analysis of three plasmids harboured in Rhodococcus erythropolis strain PR4. Environ Microbiol. 2006;8(2):334-46.

35. Čejková A, Masák J, Jirků V, Veselý M, Pátek M, Nešvera J. Potential of Rhodococcus erythropolis as a bioremediation organism. World J Microbiol Biotechnol. 2005;21(3):317-21.

36. Yarza P, Sproer C, Swiderski J, Mrotzek N, Spring S, Tindall BJ, et al. Sequencing orphan species initiative (SOS): Filling the gaps in the 16S rRNA gene sequence database for all species with validly published names. Syst Appl Microbiol. 2013;36(1):69-73.

37. Sulyok M, Krska R, Schuhmacher R. A liquid chromatography/tandem mass spectrometric multi-mycotoxin method for the quantification of 87 analytes and its application to semi-quantitative screening of moldy food samples. Anal Bioanal Chem. 2007;389(5):1505-23

38. Finnerty WR. The biology and genetics of the genus Rhodococcus. Annu Rev Microbiol. 1992;46:193-218.

39. Warhurst AM, Fewson CA. Biotransformations catalyzed by the genus Rhodococcus. Crit Rev Biotechnol. 1994;14(1):29-73.

40. Larkin MJ, Kulakov LA, Allen CC. Biodegradation and Rhodococcus - masters of catabolic versatility. Curr Opin Biotechnol. 2005;16(3):282-90.

41. Martinkova L, Uhnakova B, Patek M, Nesvera J, Kren V. Biodegradation potential of the genus Rhodococcus. Environ Int. 2009;35(1):162-77.

42. Yam KC, Okamoto S, Roberts JN, Eltis LD. Adventures in Rhodococcus - from steroids to explosives. Can J Microbiol. 2011;57(3):155-68.
43. de Carvalho CC, Costa SS, Fernandes P, Couto I, Viveiros M. Membrane transport systems and the biodegradation potential and pathogenicity of genus. Front Physiol. 2014;5:133.

44. Teniola OD, Addo PA, Brost IM, Farber P, Jany KD, Alberts JF, et al. Degradation of aflatoxin $\mathrm{B}(1)$ by cell-free extracts of Rhodococcus erythropolis and Mycobacterium fluoranthenivorans sp. nov. DSM44556(T). Int J Food Microbiol. 2005;105(2):111-7.

45. Krifaton C, Kriszt B, Szoboszlay S, Cserhati M, Szucs A, Kukolya J. Analysis of aflatoxin-B1-degrading microbes by use of a combined toxicity-profiling method. Mutat Res. 2011;726(1):1-7.

46. Cserhati M, Kriszt B, Krifaton C, Szoboszlay S, Hahn J, Toth S, et al. Mycotoxin-degradation profile of Rhodococcus strains. Int J Food Microbiol 2013;166(1):176-85.

47. Duvick J, Rood TA: Zearalenone detoxification compositions and methods US Patent 5846812 Pioneer Hi-Bred Int (USA) 1998.

48. Kriszt R, Krifaton C, Szoboszlay S, Cserhati M, Kriszt B, Kukolya J, et al. A new zearalenone biodegradation strategy using non-pathogenic Rhodococcus pyridinivorans K408 strain. PLoS One. 2012;7(9):e43608.

49. Layh N, Hirrlinger B, Stolz A, Knackmuss H-J. Enrichment strategies for nitrile-hydrolysing bacteria. Appl Microbiol Biotechnol. 1997;47:668-74.

50. Aoshima H, Hirase T, Tada T, Ichimura N, Kato H, Nagata Y, et al. Safety evaluation of a heavy oil-degrading bacterium, Rhodococcus erythropolis C2. J Toxicol Sci. 2007;32(1):69-78.

51. Crespi M, Messens E, Caplan AB, van Montagu M, Desomer J. Fasciation induction by the phytopathogen Rhodococcus fascians depends upon a linear plasmid encoding a cytokinin synthase gene. EMBO J. 1992;11(3):795-804.

52. Luhrmann A, Mauder N, Sydor T, Fernandez-Mora E, Schulze-Luehrmann J, Takai $S$, et al. Necrotic death of Rhodococcus equi-infected macrophages is regulated by virulence-associated plasmids. Infect Immun. 2004;72(2):853-62.

53. Eich E, Becker C, Sieben R, Maidhof A, Muller WE. Clavines as antitumor agents, 3: Cytostatic activity and structure/activity relationships of 1-alkyl agroclavines and 6-alkyl 6-noragroclavines. J Antibiot (Tokyo). 1986;39(6):804-12

54. Solomons RN, Oliver JW, Linnabary RD. Reactivity of dorsal pedal vein of cattle to selected alkaloids associated with Acremonium coenophialum-infected fescue grass. Am J Vet Res. 1989;50(2):235-8.

55. Wallwey C, Li SM. Ergot alkaloids: structure diversity, biosynthetic gene clusters and functional proof of biosynthetic genes. Nat Prod Rep. 2010;28(3):496-510.

56. Watanabe H, Somei M, Sekihara S, Nakagawa K, Yamada F. Dopamine receptor stimulating effects of chanoclavine analogues, tricyclic ergot alkaloids, in the brain. Jpn J Pharmacol. 1987;45(4):501-6.

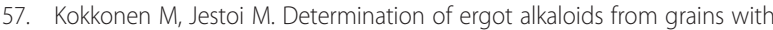
UPLC-MS/MS. J Sep Sci. 2010;33(15):2322-7.

58. Zhang $X$, Li C, Nan Z. Effects of cutting frequency and height on alkaloid production in endophyte-infected drunken horse grass (Achnatherum inebrians). Sci China Life Sci. 2011;54(6):567-71.

59. Browning Jr R, Leite-Browning ML, Smith HM, Wakefield Jr T. Effect of ergotamine and ergonovine on plasma concentrations of thyroid hormones and cortisol in cattle. J Anim Sci. 1998:76(6):1644-50.

60. Browning Jr R, Thompson FN, Sartin JL, Leite-Browning ML. Plasma concentrations of prolactin, growth hormone, and luteinizing hormone in steers administered ergotamine or ergonovine. J Anim Sci. 1997;75(3):796-802.

61. Browning Jr R, Schrick FN, Thompson FN, Wakefield Jr T. Reproductive hormonal responses to ergotamine and ergonovine in cows during the luteal phase of the estrous cycle. J Anim Sci. 1998;76(5):1448-54.

62. Klotz JL, Kirch BH, Aiken GE, Bush LP, Strickland JR. Contractile response of fescue-naive, bovine lateral saphenous veins to increasing concentrations of tall fescue alkaloids. J Anim Sci. 2010:88:408-15.

63. Mulac D, Humpf HU. Cytotoxicity and accumulation of ergot alkaloids in human primary cells. Toxicology. 2011:282(3):112-21.

64. Lyons PC, Plattner RD, Bacon CW. Occurrence of peptide and clavine ergo alkaloids in tall fescue grass. Science. 1986:232(4749):487-9.

65. Yates SG, Powell RG. Analysis of Ergopeptine Alkaloids in Endophyte-Infected Tall Fescue. J Agric Food Chem. 1988;36:337-40.

66. Porter JK. Analysis of endophyte toxins: fescue and other grasses toxic to livestock. J Anim Sci. 1995:73(3):871-80.

67. Ayers AW, Hill NS, Rottinghaus GE, Stuedemann JA, Thompson FN, Purinton PT, et al. Ruminal metabolism and transport of tall fescue ergot alkaloids. Crop Sci. 2009:49:2309-16. 
68. Klotz JL, Kirch BH, Aiken GE, Bush LP, Strickland JR. Bioaccumulation of ergovaline in bovine lateral saphenous veins in vitro. J Anim Sci. 2009;87(7):2437-47.

69. Pesqueira A, Harmon DL, Branco AF, Klotz JL. Bovine lateral saphenous veins exposed to ergopeptine alkaloids do not relax. J Anim Sci. 2014;92(3):1213-8.

70. Oliver JW, Abney LK, Strickland JR, Linnabary RD. Vasoconstriction in bovine vasculature induced by the tall fescue alkaloid lysergamide. J Anim Sci. 1993;71(10):2708-13.

71. Holden LA, Muller LD, Varga GA, Hillard PJ. Ruminal digestion and duodenal nutrient flows in dairy cows consuming grass as pasture, hay, or silage. J Dairy Sci. 1994;77(10):3034-42.

72. Ortiz XA, Smith JF, Bradford BJ, Harner JP, Oddy A. Effects of running time of a cattle-cooling system on core body temperature of cows on dairy farms in an arid environment. J Dairy Sci. 2010;93(10):4949-54.

73. Weisburg WG, Barns SM, Pelletier DA, Lane DJ. 165 ribosomal DNA amplification for phylogenetic study. J Bacteriol. 1991;173(2):697-703.

74. Cole JR, Wang Q, Fish JA, Chai B, McGarrell DM, Sun Y, et al. Ribosomal Database Project: data and tools for high throughput rRNA analysis. Nucleic Acids Res. 2014:42(Database issue):D633-42.

75. Kim OS, Cho YJ, Lee K, Yoon SH, Kim M, Na H, et al. Introducing EzTaxon-e: a prokaryotic $16 \mathrm{~S}$ rRNA gene sequence database with phylotypes that represent uncultured species. Int I Syst Evol Microbiol. 2012;62(Pt 3):716-21.

76. Teorell T, Stenhagen E. Ein Universalpuffer für den $\mathrm{pH}$-Bereich 2,0 bis 12.0. Biochem Ztschrft. 1938:299:416-9.

77. Koch C, Klatte S, Schumann P, Burghardt J, Kroppenstedt RM, Stackebrandt E. Transfer of Arthrobacter picolinophilus Tate and Ensign 1974 to Rhodococcus erythropolis. Int J Syst Bacteriol. 1995;45:576-7.

78. Goodfellow M, Alderson G. The actinomycete-genus Rhodococcus: a home for the "rhodochrous" complex. J Gen Microbiol. 1977;100:99-122.

79. Metcalfe G, Brown ME. Nitrogen fixation by new species of Nocardia. J Gen Microbiol. 1957;17:567-72.

80. Komukai-Nakamura S, Sugiura K, Yamauchi-Inomata Y, Toki H, Venkateswaran $\mathrm{K}$, Yamamoto S, et al. Construction of bacterial consortia that degrade arabian light crude oil. J Ferment Bioeng. 1996;82:570-4.

81. Kulakova AN, Larkin M, Kulakov LA. The plasmid-located haloalkane dehalogenase gene from Rhodococcus rhodochrous NCIMB 13064. Microbiology. 1997;143:109-15.

\section{Submit your next manuscript to BioMed Central and take full advantage of:}

- Convenient online submission

- Thorough peer review

- No space constraints or color figure charges

- Immediate publication on acceptance

- Inclusion in PubMed, CAS, Scopus and Google Scholar

- Research which is freely available for redistribution 